\title{
PERANAN TEKNOLOGI PENDIDIKAN DALAM PENINGKATAN MUTU PENDIDIKAN
}

\section{Suhada}

Sekolah Tinggi Agama Islam ALHIKMAH Jakarta

\section{Abstract:}

Problems related to the quality of education have long become a concern of all educational stakeholders. The stakeholders of the quality of education have thought about how to improve the quality of education in various ways. One of the efforts is by using educational technology. The educational technology can help to solve learning problems. Systemic process can be understood in twosenses: irregularorregularthatreferstoasystem. Asaregular system, the educational technology is the process that is preceded by studying the needs, formulating the objectives, identifying the possible achievement of goals, determining the possibility of selection criteria, selecting the best possibility, developing and testing the chosen possibility, carrying out development results, and evaluating the overall activities and results. As a product, the educational technologycan be understood as the processes, which are complexandintegrated thatinvolvepeople, procedures, ideas, tools, and organizations to analyze problems, find ways to solve problems, implement, assess, and manage the solutions that cover all aspects of human learning. The educational technology was born from the problems in education. It not only helps to solve the problems of learning in the school, but in the whole contexts of people's lives by developing and/or using a variety of sources. In the context of school, the technology of education evolves from what was originally known as didactic and methodical. However, 
because learning is not only in the context of school, but in the whole contexts of the community, the educational technology operates in which learning is required, either by individuals, groups or organizations.

Keywords : education, technology of education, and the quality of education.

\section{Abstrak:}

Permasalahan terkait mutu pendidikan telah sejak lama menjadi konsen bersama seluruh stake holder pendidikan. Seluruh pihak yang berkepentingan terhadap mutu pendidikan memikirkan mengenai bagaimana meningkatkan mutu pendidikan dengan berbagai cara. Salah satu upaya yang ditempuh adalahdengan menggunakan teknologi pendidikan.

Teknologi pendidikan dapat membantu memecahkan masalahmasalah pembelajaran. Proses sistemik dapat dipahami dalam dua pengertian; beraturan atau mengacu pada suatu sistem. Sebagai sistem yang beraturan, teknologi pendidikan adalah proses yang didahului dengan telaah kebutuhan, perumusan tujuan, identifikasi kemungkinan pencapaian tujuan, penentuan kriteria pemilihan kemungkinan, memilih kemungkinan terbaik, mengembangkan dan mengujicoba kemungkinan yang dipilih, melaksanakan hasil pengembangan, dan mengevaluasi keseluruhan kegiatan maupun hasilnya. Sebagai produk, teknologi pendidikan bisa dipahami sebagai perangkat proses, yang bersifat kompleks dan terpadu melibatkan orang, prosedur, ide, peralatan, dan organisasi untuk menganalisis masalah, mencari jalan untuk mengatasi permasalahan, melaksanakan, menilai, dan mengelola pemecahan masalah tersebut yang mencakup semua aspek belajar manusia. Teknologi pendidikan lahir dari adanya permasalahan dalam pendidikan. Teknologi 
pendidikan tidak hanya membantu memecahkan masalah belajar dalam konteks sekolah, namun dalam seluruh konteks kehidupan masyarakat, dengan mengembangkan dan/atau menggunakan beraneka sumber. Dalam konteks sekolah teknologi pendidikan berkembang dari apa yang semula dikenal dengan istilah didaktik dan metodik. Namun karena belajar tidak hanya dalam konteks sekolah, tetapi dalam seluruh konteks masyarakat, maka teknologi pendidikan beroperasi di mana belajar itu diperlukan, baik oleh perorangan, kelompok maupun organisasi.

Kata Kunci: pendidikan, teknologi pendidikan, mutu pendidikan. 


\section{A. PENDAHULUAN}

ebagai hasil rekayasa pengetahuan, teknologi didefinisikan S sebagai ilmu pengetahuan yang ditransformasikan ke dalam produk, proses, jasa, dan strukturorganisasi sehingga menghasilkan sesuatu yang konkrit dan siap pakai. Dewasa ini teknologi teraktualisasi dalam semua lini kehidupan sehingga tidak dapat dilepaskan dari kebutuhan umat manusia.

Sandingan teknologi adalah ilmu pengetahuan (science). Ilmu pengetahuan adalah sistimatika pemahaman manusia atas fenomena dan fakta sehingga menjadi teori atau pengetahuan. Pengetahuan manusia pada suatu masa menjadi pembeda sejarah perkembangan masyarakat dari masa ke masa. Barangkali masa kini adalah masa paling revolusioner dimana ilmu pengetahuan dan teknologi mengambil alih sebagian besar tugas kekhalifahan manusia. Keduanya bersinergi secara eksponensial, berkembang lebih cepat setiap saat, karena keduanya menjadi dasar dan alasan pengembangan ke tahap selanjutnya.

Menyimak perkembangan pesat teknologi, banyak orang percaya teknologi dapat memecahkan segala masalah meskipun seringkali melupakan akar masalahnya. Tidak terkecuali bidang pendidikan, banyak yang percaya teknologi adalah jawaban dari segala masalah pendidikan. Pandangan demikian mungkin benar, tetapi perlu dicatat bahwa masalah pendidikan adalah masalah yang kompleks. Kompleksitas pendidikan meliputi banyak hal tidak terbatas pada aspek manajerial atau praktis saja, tetapi berhubungan dengan perkembangan umum dalam kehidupan sosial termasuk isu HAM, desentralisasi pengelolaan, dan demokrasi partisipatif.

Salah satu masalah yang menjadi tantangan pendidikan nasional sekarang adalah persoalan mutu pembelajaran. Persoalan ini tidak mudah, karena meliputi semua unsur atau komponen terkait pada semua lapis kegiatan. Pembelajaran dapat didekati dengan tiga lapis, yaitu lapis mikro seperti mutu proses, lapis meso seperti mutu komponen; guru dan bahan ajar, dan lapis makro seperti kesempatan akses, kesesuaian dan efisiensi pembelajaran. ${ }^{1}$ Untuk

\footnotetext{
${ }^{1}$ Lihat Yusufhadi Miarso, Menyemai Benih Teknologi Pendidikan, Jakarta: Pusat
} 
kebutuhan praktis, fokus telaah makalah ini dibatasi pada masalah mikro, yaitu mutu proses pembelajaran.

\section{B. PEMBAHASAN}

\section{Teknologi Pendidikan}

Sejak awal perkembangannya di tahun 1920-an, teknologi pendidikan selalu dikaitkan dengan peralatan berupa audiovisual. Perkembangan ini oleh Dorris disebut sebagai "the enrichment of education trough the seeing experiences" (Pengayaan pendidikan melalui pengalaman melihat). Perkembangan ini sendiri disebut paradigma pertama. Perkembangan selanjutnya bertolak dari pendekatan sistem dan teori komunikasi. Paradigma ketiga berkembang ke arah pendekatan manajemen proses instruksional. Perkembangan keempat bergerak ke arah ilmu perilaku yang fokus kepada peserta didik.

Di awal tahun 2006, perkembangan teknologi pendidikan berkembang ke arah pemecahan masalah belajar. Paradigma ini diorientasikan untuk menjabarkan teknologi pendidikan agar dapat mengatasi problem belajar secara lebih terarah dan terkendali ${ }^{2}$ dengan memasukkan unsur ethical practice untuk memperbaiki performance pembelajaran. ${ }^{3}$

Menyimak perkembangan defenisinya, teknologi pendidikan dapat dikatakan sebagai suatu proses sistemik dalam membantu memecahkan masalah-masalah pembelajaran. Proses sistemik dapat dipahami dalam dua pengertian; beraturan atau mengacu pada suatu sistem. Sebagai sistem yang beraturan, teknologi pendidikan adalah proses yang didahului dengan telaah kebutuhan (need assesment), perumusan tujuan, identifikasi kemungkinan pencapaian tujuan, penentuan kriteria pemilihan

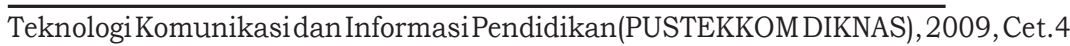

${ }^{2}$ Untuk keterangan lebih menyeluruh dapat dibaca di Robert A.Reiser \& John V.Dempsey, Trends And Issues in Instructional Design and Technology, New York: Pearson Education, Inc., 2007

${ }^{3}$ Baca lebih jelas di Alan Januszewski \& Michael Molenda, Educational Technology: A Definition with Commentary, New Jersey: Laurence Erlbaum Associates, 2008 
kemungkinan, memilih kemungkinan terbaik, mengembangkan dan mengujicoba kemungkinan yang dipilih, melaksanakan hasil pengembangan, dan mengevaluasi keseluruhan kegiatan maupun hasilnya. ${ }^{4}$

Sebagai proses yang mengacu kepada suatu sistem memandang semua unsur sebagai satu kesatuan yang terintegrasi. Teknologi pendidikan memiliki makna yang lebih luas, karena teknologi pendidikan memadukan unsur manusia, mesin, ide, prosedur, dan pengelolaannya secara terorganisir ke dalam tugas-tugas praktis. Perubahan pada satu komponen akan mempengaruhi perubahan komponen-komponen lain sehingga keseluruhannya bersifat eksponensial terhadap yang lain. Pendidikan sebagai suatu sistem integral memiliki lapisan sistemik. Lapisan itu ada yang bersifat makro, meso dan mikro. Pendidikan nasional adalah lapis makro dalam sistem pendidikan. Sementara kelas adalah lapis terbawah dari sistem mikro.

\section{Mutu Pendidikan}

Apakah yang disebut mutu? Jawaban yang diberikan atas pertanyaan ini bisa berbeda-beda. Tidak ada dua orang secara tepat dapat mendefinisikan mutu secara tepat. John Stewart, konsultan di McKinsey mengatakan, "Tidak ada definisi tunggal mengenai mutu. Berikut ini dituliskan beberapa kutipan tentang mutu. Mutu adalah perasaan menghargai bahwa sesuatu lebih baik daripada yang lain. Perasaan itu berubah sepanjang waktu dan berubah dari generasi ke generasi, serta bervariasi dengan aspek aktivitas manusia". ${ }^{5}$

Definisi lain mengenai mutu seperti yang biasa digunakan dalam manajemen berarti lebih dari rata-rata dengan harga yang wajar. Mutu juga berarti memfokuskan pada kemampuan menghasilkan produk dan jasa yang semakin baik dengan harga yang semakin bersaing. Mutu juga berarti melakukan hal-hal

\footnotetext{
${ }^{4}$ Lihat Yusufhadi Miarso, Menyemai Benih..., 2009

${ }^{5}$ Theresia Kristianty, Jurnal Pendidikan Penabur - No.04/ Th.IV / Juli 2005
} 
yang tepat dalam organisasi dengan memfokuskan hal-halyang tepat pada kesempatan pertama, organisasi menghindari biaya tinggi yang berkaitan dengan pengerjaan ulang.

Pada level mikro pendidikan yakni pembelajaran, mutu berhubungan dengan kualitas pembelajaran. Mutu pembelajaran yang diindikasi dengan efektifitas keberlangsungannya di dalam kelas. Wotruba dan Wright (1975) seperti dikutip Miarso menyebuttujuhindikator pembelajaranyang efektif; 1) pengorganisasian kuliah dengan baik, 2) komunikasi secara efektif, 3) penguasaan dan antusiasme dalam mata kuliah, 4) sikap positif terhadap mahasiswa, 5) pemberian ujian dan nilai yang adil, 6) keluwesan dalam pendekatan pengajaran, dan, 7) hasil mahasiswa yang baik. ${ }^{6}$

Pengorganisasi perkuliahan yang baik dicerminkan oleh kemampuan dosen mengorganisir perkuliahannya dengan baik meliputi perencanaan perkuliahan, penetapan tujuan, pilihan atas sumber belajar, kegiatan kelas, penugasan dan penilaian. Jaminan pencapaian indikator tersebut (jaminan mutu) bisa ditelusuri dari penilaian teman sejawat atau dari mahasiswanya.

Komunikasi berlangsung efektif, indikatornya adalah informasi yang disampaikan oleh dosen dengan mudah dapat dipahami, jelas, dan tepat. Pemakaian media dan alat audiovosual serta teknik komunikasi lain yang dapat menarik perhatian mahasiswa merupakan karakteristik dari efektifitas komunikasi pembelajaran. Kompetensi pembelajaran perlu dikuasai oleh semua pendidik. Salah satu faktor yang menentukan kualitas proses adalah kualitas pendidik yang mampu bertindak tegas, sanggup menguasai kelas, dan dapat membangkitkan rasa hormat dari peserta didik kepada pendidiknya. Secara umum pendidik wajib mampu menciptakan situasi menyenangkan.

Penguasaan dan antusiasme dalam mata kuliah. Setiap dosen dituntut untuk menguasai materi perkuliahannya agar dapat diorganisir secara sistematis dan logis. Disamping itu, dia juga dituntut untuk dapat mensinergikan pengetahuannya

\footnotetext{
${ }^{6}$ Lihat Yusufhadi Miarso, Menyemai Benih..., 2009
} 
dengan pengetahuan awal mahasiswa, mampu mengaitkan isi perkuliahannya dengan perkembangan baru dalam disiplin keilmuannya, serta mampu mengambil manfaat dari hasil penelitian yang berkaitan. Pilihan atas buku wajib dan bacaan yang tepat adalah indikator penguasaan bahan ajar. Disamping itu, dosen juga harus mampu memotivasi dan memberikan penguasaan itu kepada mahasiswa tanpa khawatir sedikit pun akan mendapat saingan.

Sikap positif terhadap mahasiswa tercermin dalam berbagai cara, misalnya apakah dosen memberi bantuan saat mahasiswa mengalami kesulitan belajar; apakah dosen dapat dihubungi di luar kelas pembelajaran; apakah dosen memberi perhatian (careness)terhadapapayangdipelajarimahasiswa.Dosendituntut untuk menguasai kompetensi pengelolaan pembelajaran. Pengelolaan pembelajaran adalah rangkaian kegiatan penyampaian bahan ajar kepada peserta didik agar dapat diterima, ditanggapi, dikuasai, dan dikembangkan dan merupakan sebuah cara atau proses timbal balik antara peserta didik dengan pendidik yang secara bersama-sama aktif melakukan kegiatan yang bertujuan membantu atau memudahkan orang lain melakukan kegiatan belajar.

Adil di dalam ujian dan penilaian. Dosen yang baik semestinya sedari awal memberitahukan dasar penilaian perkuliahan kepada mahasiswa. Hal itu dimaksudkan agar setiap mahasiswa dapat mengetahui indikator hasil yang akan dia capai. Kesesuaian soal ujian dengan bahan perkuliahan merupakan salah satu indikator adil di dalam ujian. Demikian pula feed back terhadap pekerjaan mahasiswa termasuk menetapkan nilai yang proporsional. Mahasiswa semestinya mendapat nilai B harus dinilai B dan yang semestinya mendapat nilai A harus mendapat nilai A. Sesuai tidaknya antara ujian dan penilaian dengan tujuan dan materikuliah dapat diketahui oleh teman sejawat, bahkan bisa diminta tanyakan kepada mahasiswa.

Keluwesan dalam pendekatan pengajaran. Variasi dalam pendekatan pengajaran seringkali menjadi petunjuk adanya 
gairah dalam mengajar. Pola mengajar yang bervariasi besar kemungkinan bermanfaat dalam mencapai berbagai tujuan, atau menanggapi latar belakang dan kemampuan mahasiswa. Umpamanya simulasi dan teknik permainan dapat dimanfaatkan dalam mengajar analisa, sintesa dan kemampuan berpikir kritis. Media dipakai untuk menambah daya cerna kuliah sehingga memudahkan mahasiswa menangkap pesan pembelajaran.

Hasilbelajarmahasiswayang sesuai. Hasil belajar dipengaruhi oleh berbagaifaktor dan tidak semuanya berhubungan dengan dosen. Kemampuan dan motivasi misalnya, sangat berhubungan dengan apa yang dicapai mahasiswa. Adalah penting untuk mempertimbangkan usaha belajar mahasiswa pada saat menilai efektivitas pembelajaran.

3. Peran Teknologi Pendidikan dalam Peningkatan Mutu Pendidikan

Sebagai produk, teknologi pendidikan bisa dipahami sebagai perangkat proses, yang bersifat kompleks dan terpadu melibatkan orang, prosedur, ide, peralatan, dan organisasi untuk menganalisismasalah, mencarijalanuntukmengatasipermasalahan, melaksanakan, menilai, dan mengelola pemecahan masalah tersebut yang mencakup semua aspek belajar manusia. ${ }^{7}$ Teknologi pendidikan lahir dari adanya permasalahan dalam pendidikan.

Terdapat tiga prinsip dasar dalam teknologi pendidikan sebagai acuan dalam pengembangan dan pemanfaatannya; pendekatan sistem, berorientasi pada mahasiswa, dan pemanfaatan sumber belajar. Prinsip pendekatan sistem berarti bahwa penyelenggaraan pendidikan dan pembelajaran perlu didesain dengan menggunakan pendekatan sistem. Dalam merancang pembelajaran diperlukan langkah-langkah prosedural yang terdiri dari identifikasi masalah, analisis keadaan, identifikasi tujuan, pengelolaan pembelajaran, penetapan metode, dan penetapan media evaluasi pembelajaran. Prinsip berorientasi

\footnotetext{
${ }^{7}$ Baca lebih lanjut diBarbara B. Seels, Rita C. Richey, Instructiuonal Technology: The Definition and Domains of The Field, Washington DC: AECT, 1994
} 
pada mahasiswa berarti pembelajaran hendaknya memusatkan perhatiannya pada peserta didik dengan memperhatikan karakteristik, minat, potensi dari mahasiswa. Prinsip pemanfaatan sumber belajar berarti dalam pembelajaran hendaknya dapat memanfaatkan sumber belajar untuk mengakses pengetahuan dan keterampilan yang dibutuhkan. Keberhasilan pembelajaran diukur dari bagaimana mahasiswa dapat belajar, dengan cara mengidentifikasi, mengembangkan, mengorganisasi, serta menggunakan segala macam sumber belajar. Dengan demikian upaya pemecahan masalah dalam pendekatan teknologi pendidikan dilakukan dengan mendayagunakan sumber belajar. ${ }^{8}$

Teknologi pendidikan sebagai disiplin keilmuan berpegangan pada serangkaian postulat sebagai berikut: 1) Lingkungan kita senantiasa berubah. Perubahan itu ada yang direkayasa, ada yang dapat diperkirakan, namun sebagian besar tidak dapat kita ketahui sebelumnya. 2) Jumlah penduduk semakin bertambah, meskipun dengan prosentase yang mengecil. Mereka semua perlu belajar, dan belajar itu berlangsung seumur hidup, di mana saja, dan dari siapa saja. 3) Sumber-sumber tradisional semakin terbatas, karena itu harus dimanfaatkan sebaik mungkin dan seoptimal mungkin. Kecuali itu harus pula diciptakan sumber baru, dan didayagunakan sumber yang masih belum terpakai. 4) Adalah hak setiap pribadi untuk dapat berkembang semaksimal mungkin, selaras dengan perkembangan masyarakat dan lingkungan 5) Masyarakat berbudaya teknologi, yaitu bahwa teknologi merupakan bagian yang tertanam (embedded) dan tumbuh dalam setiap masyarakat, dengan kadaryang berbeda.

Berdasarkan postulat itu kita ketahui bahwa ada serangkaian gejalabelajaryangbelumtergarapsecarabaik. Gejalaituadalah: 1) Adanya sejumlah besar orang yang belum terpenuhi kesempatan belajarnya, baik yang diperoleh melalui suatu lembaga khusus, maupun yang dapat diperoleh secara mandiri. 2) Adanya berbagai sumber baik yang telah tersedia maupun yang dapat direkayasa, tetapi belum dapat dimanfaatkan untuk keperluan

${ }^{8}$ Lihat Barbara B. Seels, Instructiuonal Technology..., 1994 
belajar. 3) Perlu adanya suatu usaha khusus yang terarah dan terencana untuk menggarap sumber-sumber tersebut agar dapat terpenuhi hasrat belajar setiap orang. 4) Perlu adanya pengelolaan atas kegiatan khusus dalam mengembangkan dan memanfaatkan sumber untuk belajar tersebut secara efektif, efisien dan selaras.

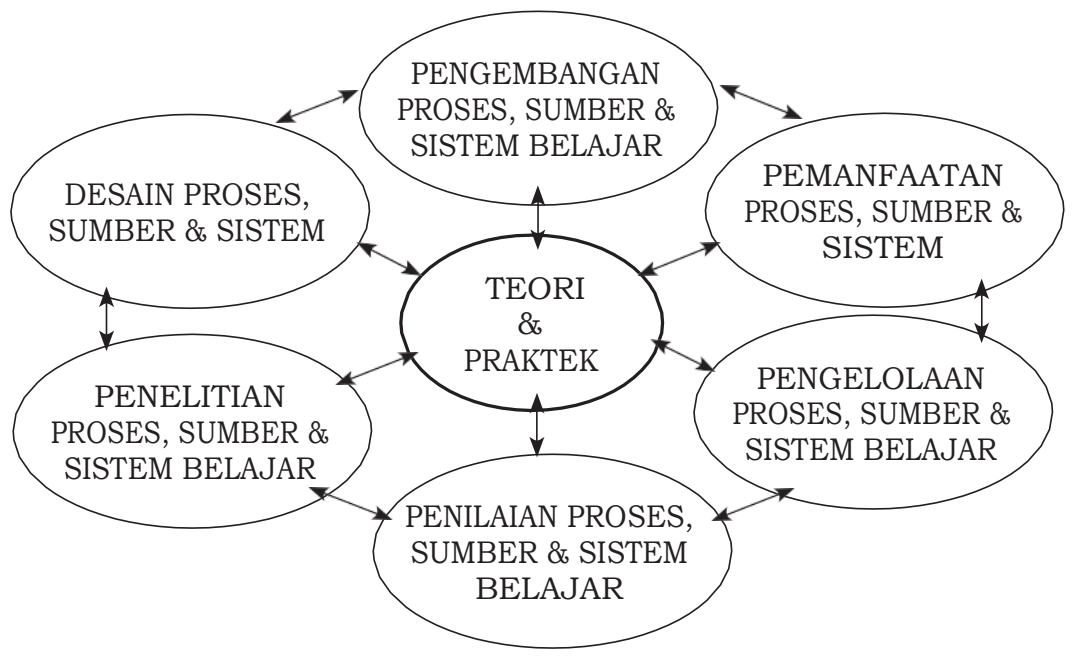

Gambar 1: Siklus garapan teknologi pendidikan

Keempat gejala ini merupakan rujukan bidang garapan teknologi pendidikan (lihat gambar 1) yang antara lain berfungsi untuk memberikan kesempatan belajar sesuai dengan kondisi dan kebutuhan, termasuk menjangkau peserta didik/pembelajar di tempat yang jauh dan terasing dan melayani sejumlah besar dari mereka yang belum memperoleh kesempatan pendidikan, meningkatkan efektivitas dan daya tarik belajar, mendayagunakan berbagai sumber untuk keperluan belajar, serta untuk memperoleh akses terhadap berbagai informasi sebagai bagian dari tuntutan belajar.

Teknologi pendidikan didefinisikan sebagai teori dan praktek dalam merancang, mengembangkan, mendayagunakan, mengelola, menilai, dan meneliti proses, sumber, dan sistem belajar pada manusia. Teknologi pendidikan berpegang pada enam pendekatan dalam menjalankan fungsinya, yaitu : 
1) Pendekatan isomeristik berupa penggabungan berbagai kajian/bidang keilmuan (teori sistem, psikologi, komunikasi, informatika, ekonomi, manajemen, rekayasa teknik dsb.) ke dalam suatu kebulatan tersendiri; 2) Pendekatan bersistem dan mensistem, dengan memandang sesuatu secara menyeluruh serta berurutan dan terarah dalam usaha memecahkan persoalan; 3) Pendekatan sinergistik yang menjamin adanya nilai tambah dari keseluruhan kegiatan dibandingkan dengan bila kegiatan itu dijalankan sendiri-sendiri; 4) Pendekatan efektivitas dan efisiensi dengan jalan mendayagunakan sumber yang sengaja dikembangkan dan sumber yang tersedia; 5) Pendekatan produktivitas dengan memberikan masukan tambahan atau masukan baru menggantikan yang lama dengan hasilyang meningkat; 6) Pendekatan inovatif dengan mengkaji permasalahan secara holistik dan kemudian mencari jawaban baru yang belum ada sebelumnya.

Berdasarkan pendekatan itu maka teknologi pendidikan tidak hanya membantu memecahkan masalah belajar dalam konteks sekolah, namun dalam seluruh konteks kehidupan masyarakat, dengan mengembangkan dan/atau menggunakan beraneka sumber. Dalam konteks sekolah teknologi pendidikan berkembang dari apa yang semula dikenal dengan istilah didaktik dan metodik. Namun karena belajar tidak hanya dalam konteks sekolah, tetapi dalam seluruh konteks masyarakat, maka teknologi pendidikan beroperasi di mana belajar itu diperlukan, baik oleh perorangan, kelompok maupun organisasi.

Kontribusi teknologi pendidikan dalam pembaharuan sistem pendidikan dan pembelajaran dapat dibedakan dalam lima kategori yaitu: 1) Penyediaan tenaga profesi yang kompeten untuk memecahkan masalah belajar; 2) Pengintegrasian konsep, prinsip dan prosedur dalam sistem pendidikan; 3) Pengembangan sistem belajar-pembelajaran yang inovatif; 4) Penggunaan teknologi komunikasi dan informasi dalam proses belajar dan pembelajaran; 5) Peningkatan kinerja organisasi dan sumber daya manusia agar lebih produktif. 
Kelimakategoriinidapat dibedakan tetapitidakterpisahkan karena saling berkaitan dan menunjang. Kategori pertama meliputi pendidikan dan pelatihan tenaga dalam bidang teknologi pendidikan. Pendidikan keahlian pada jenjang Sarjana telah dimulai pada tahun 1976, dan Pascasarjana pada tahun 1978. Sedangkan pelatihan tenaga telah dimulai tahun 1972 meliputi tenaga terampil dalam memproduksi media pembelajaran, hingga tenaga terampil dalam melaksanakan proses pembelajaran pada semua jenis, jalur dan jenjang pendidikan. Termasuk pada jenjang pendidikan tinggi adalah program PPAI (Peningkatan dan Pengembangan Aktivitas Instruksional) yang antara lain menyelenggarakan pelatihan keterampilan pembelajaran dosen perguruan tinggi.

Kategori kedua meliputi konsep pembelajaran yang menggantikan pengajaran, konsep sumber belajar, konsep belajar berbasis aneka sumber, prinsip pengembangan potensi peserta didik yang beragam, prinsip pendekatan dari bawah (bottom-up approach), serta prosedur proses pembelajaran dan penilaian. Semua konsep, prinsip, dan prosedur ini telah menjadi bagian integral dalam sistem pendidikan nasional, dan tertuang dalam UU Sisdiknas No. 20 Tahun 2003 serta berbagai peraturan turunannya, seperti standar proses pembelajaran, standar sarana dan prasarana dan standar penilaian. Kategori ketiga meliputi pengembangan berbagai pola pembelajaran alternatif karena adanya dorongan internal kebutuhan akan pendidikan. Pola itu meliputi SMPTerbuka, belajar di rumah (homeschooling), pembelajaran terprogram (PAMONG), pembuatan berbagai paketatau sumber belajar (Kejar Paket A, Bdan C, moduluntuk belajar mandiri, media audiovisual dll.), dan pemanfaatan lingkungan untuk belajar (community and environment-based learning). Kategori keempat terkait erat dengan pola ketiga, namun lebih didasarkan pada faktor eksternal, yaitu tersedianya berbagai sarana yang ada dalam masyarakat, terutama teknologi informasi dan komunikasi. Bentuk penerapannya meliputi serial program siaran televisi ACI (Aku Cinta Indonesia, 19841985), penataran guru melalui siaran radio dan televisi, paket 
belajar multimedia, pembelajaran berbantuan komputer (CAI= computer assisted instruction), dan pengembangan sistem belajar berjaringan (e-learning dan online learning), untuk semua jalur, jenis dan jenjang pendidikan.

Kategori kelima terutama ditujukan untuk peningkatan kemampuan mereka yang berkarya dalam masyarakat atau dalam dunia dan lapangan kerja. Kemampuan itu sendiridapat dibedakan ke dalam tiga kelompok, yaitu: 1) kemampuan memperoleh informasi yang diperlukan; 2) kemampuan untuk mengolah dan menggunakan informasi hingga menjadi pengetahuan yang mendasari kebijakan (wisdom); dan 3) kemampuan untuk membentuk sikap positif terhadap diri dan lingkungannya. Jelaslah bahwa peran penyampaian misi dan informasi pendidikan hanya merupakan sebagian dari peran teknologi pendidikan.

\section{PENUTUP}

Perkembangan masyarakat manusia semakin menegaskan peran teknologi pendidikan dalam peningkatan mutu pendidikan disemualevel pendidikan. Padalevel makro, teknologi pendidikan berperan dalam mendesain konsep dan pelaksanaan pendidikan secara nasional. Akses pendidikan bagi semua tidak dapat didekati secara konvensional, namun butuh sentuhan teknologi yang bisa menjamin semua warga negara menikmati pembelajaran yang menjadi haknya sebagai warga negara.

Pada level mikro, teknologi pendidikan berperan serta dalam pencapaian mutu pembelajaran. Mutu pembelajaran indikatornya harus terukur. Jaminan pencapaian indikator-indikator itu hanya bisa didekati melalui pendekatan teknologi dalam pengertian sebenarnya, tidak terbatas pada tools pembelajaran semata, tetapi terintegrasi secara sistemik dan pemanfaatan sumber belajar yang bervariasi.[] 


\section{DAFTAR REFERENSI}

Alexander, S., "Teaching andLearning on the WordWideWeb", diakses dari http://www.scu.edu.au/Ausweb95/papers/education/ alexander, pada 29 Oktober 2010

Geisert, Paul G., dkk, Teacher, Computers, and Curriculum: Micro computer in the classroom, Needham: Library of Congress Cataloging in publication, dari http://www.umich. edu/ ed626/Gerlach_Ely/ge_main.htm, diakses pada 28 Oktober 2010

Januszewski, Alan, dan Michael Molenda, Educational Technology: ADefinition with Commentary, New Jersey: Laurence Erlbaum Associates, 2008

Kristianty, Theresia, Jurnal Pendidikan Penabur - No.04/ Th.IV / Juli 2005

Miarso, Yusufhadi, Menyemai Benih Teknologi Pendidikan, Jakarta: Pusat Teknologi Komunikasi dan Informasi Pendidikan(PUSTEKKOM DIKNAS), 2009, Cet.4

Reiser, Robert A., dan John V.Dempsey, Trends And Issues in Instructional Design and Technology, New York: Pearson Education, Inc., 2007

Seels, Barbara B., dan Rita C. Richey, Instructiuonal Technology: The Definition and Domains of The Field, Washington DC: AECT, 1994 
Suhada

50 HIKMAH, Vol. XIII, No. 2, 2017 